\title{
The effect of an online video intervention 'Movie Models' on specific parenting practices and parental self-efficacy related to children's physical activity, screen-time and healthy diet: a quasi experimental study
}

Sara De Lepeleere* ${ }^{*}$, Ilse De Bourdeaudhuij, Greet Cardon and Maïté Verloigne

\begin{abstract}
Background: In children, being sufficiently physically active, having low levels of screen-time and having a healthy diet are largely influenced by parenting practices. Children of parents applying positive parenting practices are at lower risk for overweight and obesity. Therefore, we investigated the effect of a health promoting online video intervention for parents ('Movie Models') on children's physical activity (PA), screen-time and healthy diet, and on specific parenting practices and parental self-efficacy related to these parenting practices. The online videos are delivered to parents of primary schoolchildren, and were based on real-life scenarios.
\end{abstract}

Methods: A two-armed, quasi experimental design was used. Parents of primary schoolchildren were recruited between November and December 2013 by spreading an appeal in social media, and by contacting primary schools. Participating parents were predominantly of high socio-economic status (SES) (83.1\%), and only $6.8 \%$ of children were overweight/ obese. Intervention group participants were invited to watch online videos for 4 weeks. Specific parenting practices, parental self-efficacy, PA, screen-time and healthy diet of the child were assessed at baseline (T0), at one (T1) and at four (T2) months post baseline. Repeated Measures (Multivariate) ANOVAs were used to examine intervention effects. The potential moderating effect of age and gender of the child and parental SES was also examined.

Results: Between T0 and T2, no significant intervention effects were found on children's PA, screen-time or healthy diet. Most significant intervention effects were found for more complex parenting practices (e.g., an increase in motivating the child to eat fruit). Subgroup analyses showed that the intervention had more effect on the actual parenting practices related to PA, screen-time and healthy diet in parents of older children (10-12 years old), whereas intervention effects on parental self-efficacy related to those behaviors were stronger in parents of younger children (6-9 years old).

Conclusions: 'Movie Models' was effective in increasing some important parenting practices and parental self-efficacy related to PA, screen-time and healthy diet in children. Therefore, the current study is an important first step in promoting effective parenting-related factors, and possibly increasing children's healthy diet and PA, and decreasing screen-time.

Trial registration: NCT02278809 in ClinicalTrials.gov on October 28, 2014 (retrospectively registered).

Keywords: Parenting, Parenting practices, Parental self-efficacy, Parent, Child, Physical activity, Screen-time, Healthy diet

* Correspondence: Sara.DeLepeleere@UGent.be

Department of Movement and Sport Sciences, Ghent University,

Watersportlaan 2, 9000 Ghent, Belgium 


\section{Background}

Childhood overweight and obesity are associated with an avoidable burden of disease [1] such as cardiovascular diseases, diabetes, overweight/obesity, cancer, depression, fear, stress and poor self-image [2, 3] in adulthood. Being sufficiently physically active, having low levels of 'screen-time' (e.g., watching TV, playing video games), and having a healthy diet (i.e., eating a variety of foods which is essential to achieve adequate macro- and micronutrient intakes [4]), positively affect both physical and mental health, and can prevent overweight and obesity among children [5-7]. However, $83.2 \%$ of European boys and $95.4 \%$ of girls do not achieve the guidelines of at least $60 \mathrm{~min}$ of moderate to vigorous physical activity (PA) on most days of the week [8]. Furthermore, European children spend on average more than $2 \mathrm{~h}$ /day on screen time (TV and computer activities combined) [9], despite current guidelines recommending to spend no more than $2 \mathrm{~h}$ per day in recreational screen time [10]. European children also engage frequently in dietary behaviors that are regarded as potential risk behaviors for becoming overweight or obese. Many children skip breakfast on one or more days per week and the mean intake of sugar-sweetened beverages is high [9]. These data highlight the need for interventions designed to improve children's healthy behaviors.

An increasing number of studies highlight the importance of parents in helping to shape healthy behaviors in their children [3, 11-14]. Parents may impact on their children's behavior through parenting practices [15], which are specific practices of parents aiming to positively influence the child's behavior, or through parenting styles [15], which refer to the broader emotional and relational climate in which these practices occur. Thus, parenting practices generally address what parents do, while parenting styles address how they do it. It is shown that parenting practices may be more effective when embedded in a positive parenting environment [16, 17]. Furthermore, literature shows that the authoritative parenting style, characterized by reasonable demands and high responsiveness, is associated with positive child and adolescent outcomes across multiple domains [11]. Therefore, parents can be an important focus of newly developed interventions to change children's behavior.

Additionally, behavior change interventions that have been based on psychological theory tend to be more successful than those that have not [18]. Literature shows that Self Determination Theory (SDT) could provide a useful basis for interventions because of its conceptual similarity to the authoritative parenting style $[11,19]$. According to SDT, all human beings have the fundamental need to feel related, competent and autonomous in order to develop and function optimally [20, 21]. Another important concept in SDT is internalization, the process by which individuals gradually transform certain externally reached beliefs, attitudes or behaviors into personally appreciated ones. As initially uninteresting activities become more internalized, they are performed with a larger feeling of autonomy, psychological freedom or self-determination [22]. However, evidence for effective, theory-based parenting interventions focusing on parenting practices to promote healthy behavior in children is still scarce [11, 23]. To date, most intervention programs have been situated within the school area because the existing organizational, social and communication structures provide opportunities for regular health education, and have the potential to reach children and their families across the social spectrum. Intervention programs try frequently to teach parents important parenting practices by distributing flyers, newsletters or homework tasks via their child's school [24-26]. Unfortunately, a number of systematic reviews and meta-analyses have found that parents are difficult to reach with those strategies and interventions delivered within the school setting have shown limited effects [27-31]. This highlights a need for new, more effective approaches. In the study of Jago et al., parents of 6 to 8 year-old children attended an 8 week parenting program focusing on physical activity and screen-viewing (Teamplay). Each 2-h session consisted of three main topics and time for refreshments, games, parent feedback and the introduction of some tasks to be completed at home. Parenting aspects were aligned with SDT to encourage parents to use autonomy-supportive rather than controlling parenting strategies. Teamplay appeared to be a promising parenting program although it was highlighted that an internet-based maintenance program might be needed to maintain the intervention effects [19]. Furthermore, several benefits of using the internet in interventions are reported: being anonymous as a parent, information is available $24 \mathrm{~h}$ per day (most people have access to the internet $24 / 7$ via their laptop, tablet, smartphone, etc.), the possibility to reach a wider audience and to increase access to organizations without an increase in costs [32]. Ruiter et al. also reported some strengths of a web-based e-learning program: parents can follow the program in their own home, at a time that suits best for them and at their own pace. Moreover, parents are not obliged to engage in a complex, time-consuming program [33]. Onnerfalt et al. developed a website for parents of preschool children to provide general information about nutrition and exercise recommendations, and also offered a parent support section. The website was used to prepare parents for a group intervention with the purpose of supporting them to accomplish preferred lifestyle changes, and to try new parenting techniques [34]. Also in the 'Ehealth4Uth Healthy Toddler' study of Raat et al., parents received an invitation to visit a website 1 month prior to the regular health care visit at child age 18 months. This 
way, parents obtained tailored parenting and health information on healthy child nutrition and activity behaviors. Furthermore, the general attitudes of the parents toward overweight prevention from early age on, and whether parents applied the recommended parental practices were examined. Results showed that the majority of the parents indeed understood the message, and viewed the message as useful and applicable [35]. Preliminary research in Flanders (Belgium) in which focus groups with parents and discussions with stakeholders and parenting experts were held, highlighted an interest in online videos as a way to learn how to perform effective parenting practices [36]. In light of the evidence reported above, an online intervention 'Movie Models' was developed. 'Movie Models' is based on the principles of SDT, and developed according to the Intervention Mapping Protocol [37]. The main goal of the intervention is to increase children's PA, limit their screen-time, and improve their dietary behaviors, to prevent childhood overweight and obesity in the long run. Because parenting practices and parental self-efficacy might have a bridging function between the intervention and the child's behavior, parenting practices and parental self-efficacy are examined as secondary outcomes.

Therefore, the first aim of the current study was to evaluate the effect of 'Movie Models' on the child's behavior (PA, screen-time, healthy diet). Secondly, the intervention effect on parenting practices and parental self-efficacy was investigated. Finally, because it has been found that characteristics of parents and characteristics of the child that influence the parent-child relationship may influence parenting practices in the context of energy-related behaviors [11], we also examined if the intervention effects differed according to age and gender of the child and parental socio-economic status (SES).

\section{Methods}

\section{Study design and setting}

A two-armed, quasi experimental design was conducted in Flanders (i.e., the Dutch speaking part of Belgium). Ethical approval was provided by the Ethics Committee of the Ghent University Hospital (B670201214212).

\section{Participants and recruitment}

A convenience sample of parents of primary schoolchildren was recruited by using different channels. Firstly, principals of 36 primary schools in Flanders were contacted personally by the researchers. In total, 30 schools (83\%) agreed to participate. The only reason to decline was 'not enough time' $(n=6)$. In November-December 2013, flyers $(n=5077)$ to invite parents to participate were distributed in the participating schools to all 6- to 12-year old children to take home. However, because recruitment via schools was difficult, it was decided to also spread an appeal to participate by (social) media: two Flemish magazines for parents ('Klasse' and 'De Gezinsbond') and the Facebook page of EXPOO (expertise center for parenting support). Because it is unknown how many parents were reached by the invitation appeals, it is not possible to calculate a reliable response rate. Parents who wanted to participate had to send an email to the researcher. Afterwards, they were sent an information letter which contained information on the goal, the inclusion/exclusion criteria (having at least one primary schoolchild, availability of internet access at home, the primary school child is not on a diet nor has a physical disability), the content, the course, the starting and ending procedure, the risks, the advantages and confidentiality of the study. Furthermore, participants were sent the link to the online questionnaire, and were informed that by completing this online questionnaire, they gave consent to participate in the study. The recruitment of parents was ended by the second week of January 2014.

\section{Development of the 'Movie Models' intervention}

The development of the 'Movie Models' intervention, based on the Intervention Mapping Protocol, is described in detail elsewhere [38], but will be briefly discussed in this paper. After consultation of parents in focus group discussions and a parenting expert panel, 22 online videos about difficult parenting situations were developed. These videos (5 on PA, five on screen-time and 12 on healthy diet (water, breakfast, fruit, vegetables and buying healthy food in the supermarket)) each lasted about $2 \mathrm{~min}$. In the videos, a difficult child-parent situation (concerning PA, screen-time or diet) is followed by an appropriate reaction of the parent (based on Self Determination Theory and Social Cognitive Theory which both support the principles of authoritative parenting). Afterwards, a narrator explains the parenting practices used in the video. This way, parents who watch the videos can learn effective parenting strategies related to PA, screen-time and diet usable in daily life through the modeling technique. Furthermore, parental attitude and parental self-efficacy concerning adopting the parenting strategies can be enhanced. The online videos are in Dutch, and can be watched on: www.gezondopvoeden.ugent.be. Table 1 shows a brief overview of the main messages of the 22 videos.

\section{Description of the 'Movie Models' intervention}

After completing the online baseline questionnaire, participants were allocated to the intervention or control group (waitlist). Parents recruited via the appeal on social media were allocated randomly to the intervention or control group by computer randomization. Parents recruited within the same school were allocated to the same group (intervention or control) to avoid diffusion of intervention effects. Participants assigned to the 
Table 1 Overview of the content of the 22 online parenting videos

\begin{tabular}{|c|c|c|c|}
\hline Behavior & Video & Message & $\begin{array}{l}\text { Week in which video } \\
\text { was offered to parents }\end{array}$ \\
\hline \multirow[t]{3}{*}{ Water } & Guideline & $\begin{array}{l}\text { Video on the guideline for children to drink at least five big or six small glasses a day, } \\
\text { why drinking water is important, ... }\end{array}$ & 1 \\
\hline & Tip 1 & $\begin{array}{l}\text { Let your child drink water limitless, and make rules concerning soft drink consumption } \\
\text { (e.g., always drink water at dinner, except in weekends) }\end{array}$ & 1 \\
\hline & Tip 2 & $\begin{array}{l}\text { Motivate your child to drink water (e.g., fill your child's favorite goblet with water, and } \\
\text { give it to him/her when he/she plays outdoors) }\end{array}$ & 1 \\
\hline \multirow[t]{3}{*}{ Fruit } & Guideline & $\begin{array}{l}\text { Video on the guideline for children to eat at least two or three pieces of fruit a day, } \\
\text { why eating fruit is important, ... }\end{array}$ & 1 \\
\hline & Tip 1 & Reinforce your child when he/she eats fruit (e.g., by giving a compliment) & 1 \\
\hline & Tip 2 & $\begin{array}{l}\text { Make sure that healthy fruit snacks can be eaten easily (e.g., peel and cut the fruit into } \\
\text { slice before giving it as a snack to school) }\end{array}$ & 1 \\
\hline \multirow[t]{3}{*}{ Vegetables } & Guideline & $\begin{array}{l}\text { Video on the guideline for children to eat at least five to twelve spoons of vegetables } \\
\text { a day, why eating vegetables is important, ... }\end{array}$ & 2 \\
\hline & Tip 1 & $\begin{array}{l}\text { Motivate your child each time to taste a vegetable he/she does not like (e.g., it can be } \\
\text { necessary to present a vegetable more than } 10 \text { times to your child before he/she likes it). }\end{array}$ & 2 \\
\hline & Tip 2 & $\begin{array}{l}\text { Make sure that healthy vegetable snacks can be eaten easily (e.g., peel and cut the } \\
\text { vegetable into slice before giving it as a snack to school) }\end{array}$ & 2 \\
\hline Breakfast & Tip 1 & $\begin{array}{l}\text { Make sure breakfast is a peaceful and calm moment (e.g., the parent can make lunch } \\
\text { the evening before so he/she can have breakfast together with the child.) }\end{array}$ & 2 \\
\hline \multirow[t]{2}{*}{ Supermarket } & Tip 1 & Involve your child in buying fruit and vegetables in the supermarket. & 2 \\
\hline & Tip 2 & $\begin{array}{l}\text { Limit buying unhealthy food as much as possible (e.g., enter into agreements } \\
\text { concerning buying cookies before going to the supermarket). }\end{array}$ & 2 \\
\hline \multirow[t]{5}{*}{ PA } & Guideline & $\begin{array}{l}\text { Video on the guideline for children to be physically active for at least } 1 \mathrm{~h} \text { a day, why } \\
\text { PA is important, ... }\end{array}$ & 3 \\
\hline & Tip 1 & $\begin{array}{l}\text { Try to be active in as many ways as possible during the day (e.g., by accompanying } \\
\text { your child by bike to school) }\end{array}$ & 3 \\
\hline & Tip 2 & $\begin{array}{l}\text { Be a good model for your child by being physically active together with him/her } \\
\text { (e.g., propose some activities you can do together). }\end{array}$ & 3 \\
\hline & Tip 3 & $\begin{array}{l}\text { Motivate your child to be physically active (e.g., when he/she suddenly does not want } \\
\text { to go to the youth movement anymore). }\end{array}$ & 3 \\
\hline & Tip 4 & $\begin{array}{l}\text { Make physical activities pleasant for your child (e.g., let him/her choose to walk, } \\
\text { roller-skate, ride a scooter...) }\end{array}$ & 3 \\
\hline \multirow[t]{4}{*}{ Screen-time } & Guideline & $\begin{array}{l}\text { Video on the guideline for children to limit screen time to } 2 \mathrm{~h} \text { a day, why sedentary } \\
\text { behavior is unhealthy, ... }\end{array}$ & 4 \\
\hline & Tip 1 & $\begin{array}{l}\text { Enter into agreements about screen-time, and be consistent (e.g., let your child play on } \\
\text { his/her Nintendo for } 30 \mathrm{~min} \text {, and make sure he/she stops playing after half an hour). }\end{array}$ & 4 \\
\hline & Tip 2 & $\begin{array}{l}\text { Do not use TV or computer as a mean to keep your child calm (e.g., when you want to } \\
\text { do the housekeeping). }\end{array}$ & 4 \\
\hline & Tip 3 & $\begin{array}{l}\text { Do pleasant activities together with your child instead of watching TV (e.g., on a sunny } \\
\text { Sunday afternoon you can frisbee, cycle, go to the park,...) }\end{array}$ & 4 \\
\hline General & Time-out & Video on using time-out when your child really misbehaves. & 4 \\
\hline
\end{tabular}

intervention group were invited to watch the online parenting videos on a secured website over 4 weeks. At the start of the intervention period, the parenting videos concerning drinking water $(n=3)$ and eating fruit $(n=3)$ were put online. In the second week of the intervention, the videos concerning eating vegetables $(n=3)$, having breakfast $(n=1)$ and the supermarket $(n=2)$ were added to the website. During week three, parents could also watch the videos on PA $(n=5)$, and in week four the videos on screen-time $(n=5)$ were available.
Intervention group parents were sent an invitation email every week to watch the new online videos. Furthermore, they were asked to fill out a short online process evaluation questionnaire (5-10 questions) on the videos that they watched the preceding week.

One (T1) and four (T2) months post baseline, both intervention and control group participants received the link to the same online questionnaire. The waiting list control group received no additional input during the period of the intervention, but got access to the online 
videos at the end of the study. As incentive, five gift vouchers were randomly distributed among parents who completed all questionnaires.

\section{Measures}

At the beginning of the online questionnaire, it was mentioned that if parents had more than one child in primary school, they could choose for which child they wanted to complete the questionnaire. The questionnaire assessed demographic variables, parentreported child's PA, screen-time and healthy diet (primary outcome), specific parenting practices (secondary outcome) and parental self-efficacy concerning these practices (secondary outcome). All measures were assessed at baseline (T0), at the end of the intervention (T1, 1-month post baseline) and 3 months after the intervention had ended (T2, 4-months post baseline) to determine any change in parenting practices, parental self-efficacy and the behavior of the child.

\section{Demographic variables}

Age, gender, weight and height of the child, weight and height of both parents and number of children living in the house were reported in the questionnaire. The reported educational level of the parent who completed the questionnaire was used as a proxy for Socio-Economic Status (SES). Low SES was determined as parents having no higher education and medium to high SES as parents having higher education (vocational college, university or post-academic) [39]. Children's body mass index (weight/ height squared) was calculated from the parent-reported height and weight of the child. To define if a child was overweight or obese, age and sex specific cut off points developed by Cole et al. [40] for children from 2 to 18 years were used [40].

\section{Child's behavior}

Levels of children's PA and screen-time were assessed by the questionnaire adopted from the Flemish Physical Activity Questionnaire which has moderate criterion validity (Pearson correlation coefficient between 0.22 and 0.45 with accelerometers) [41, 42]. Total PA was assessed by adding up minutes spent in active transportation (to school and in leisure time) and time spent in sports (at school and during leisure time) per week. Screen-time was defined as the total time spent watching TV, playing computer games and using game consoles per week. The dietary behavior of the child was assessed by the Food Frequency Questionnaire which has a good criterion validity (Pearson correlation coefficients between 0.5 and 0.7 with estimated diet records) [43]. Consumption of fruit, vegetables, water, soft drinks and snacks were measured on a seven-point scale ranging from ' $1=$ never' to ' $7=$ more than once every day'.

\section{Specific parenting practices}

Because we aimed to measure very specific parenting practices related to PA, screen-time and healthy diet, a new scale was developed based on the validated Parental Support For Physical Activity Scale (Cronbach's alpha $=0.78$; test-retest reliability: $R=0.81$ ) [44], the Parenting Strategies for Eating and Activity Scale [45] (Cronbach's alpha $=0.81-0.82)$ and the Parental Feeding Style Questionnaire (Cronbach's alpha $=0.67-0.83$; test-retest reliability: $R=0.76-0.83$ ) [46]. Most items were assessed on a two-point scale (disagree-agree) or a five-point Likert scale ranging from 'never' to 'always' (Additional file 1: Table S1).

Parental self-efficacy concerning the specific parenting practices The parental self-efficacy questions were created analogous to the questions on the specific parenting practices, and were based on the translation of the GEMS (Girls Health Enrichment Multisite Study) questionnaire (Cronbach's alpha $=0.52-0.62$; test-retest reliability: $R=0.61-0.82$ ) [47], the questionnaire of parental self-efficacy for enhancing healthy lifestyles in their children (Cronbach's alpha $=0.94$; test-retest reliability: $R=0.94$ ) [48] and Section $L$ of the Aventuras Para Ninos parent survey (Cronbach's alpha $=0.73-0.87$ ) [49]. The items were assessed by using a five-point answering format ranging from 'completely disagree' to 'completely agree' (Additional file 1: Table S1). These items were recoded to obtain a higher score when parents had a higher self-efficacy. The descriptive statistics of the specific parenting-related factors at baseline can be found elsewhere [50] (De Lepeleere S, Verloigne M, Cardon G, De Bourdeaudhuij I: Do Specific Parenting Practices and Parental Self-Efficacy associate with Beverages Intake among Belgian Primary Schoolchildren?, unpublished).

\section{Data analysis}

Power analyses (powered on children's PA, sedentary behavior and healthy diet, i.e., the primary outcomes of the study) revealed that 254 families were sufficient to investigate the possible effect of the 'Movie Models' intervention (power $=0.80 ; \alpha=0.01$; effect size $=0.40$ ).

Preliminary analyses consisted of descriptive statistics of sample characteristics and normality of key variables was checked. Because PA and screen-time at all three measurement moments were skewed, square root transformations were used to improve normality. For ease of interpretation, non-transformed mean values are reported in the tables.

Participants' characteristics at baseline were compared by independent sample t-tests for quantitative variables and by chi-square tests for qualitative variables to detect baseline differences between the control and the intervention group, and to conduct a drop-out analysis. Because baseline characteristics did not differ significantly 
between intervention and control group, they were not used as covariates in further analyses. Intervention effects on children's PA, screen-time, fruit, vegetable, water, soft drink and snack consumption were examined by conducting a Repeated Measures Multivariate ANOVA. Repeated Measures ANOVAs with time as within factor (differences between pre and posttest and between pre and follow-up) and condition (intervention group, control group) as between factor were conducted to examine intervention effects on parenting practices and parental self-efficacy. To examine potential moderating effects of children's age (69 versus 10-12 years old), children's sex (boys versus girls) and parental SES (low versus high SES), a three-way interaction effect (time* condition"moderator) was investigated for each outcome. In case of a significant three-way interaction effect for an outcome variable, analyses were stratified by the respective moderator. To consider the effect size of (borderline) significant interaction effects, we have reported Cohen's d statistic (effect sizes 0.20-0.49 were considered small, $0.50-0.79$ moderate and $\geq 0.80$ large) [51]. Values are only reported in the text, not in the tables. All Repeated Measures (Multivariate) ANOVAs were performed using IBM SPSS Statistics 21.0. Due to the multiple tests that were performed, and to find a balance between Type I and Type II mistakes, only $p$-values $<0.01$ were considered significant. $P$-values $\geq 0.01$ and $<0.05$ were considered borderline significant. All analyses were completer only analyses, and were conducted using SPSS (SPSS version 20.0, IBM corp., Armonk, NY; 2011). The dataset is available as Additional file 2: Table S4.

\section{Results}

\section{Study characteristics}

The recruitment process resulted in 238 parents who agreed to participate. Of these parents, 207 (response rate of $87.0 \%$ ) filled out the online questionnaire at baseline. Fifty-five (52.9\%) intervention participants and 80 (77.7\%) control participants completed 1-month post baseline measurements. Fifty-four (51.9\%) intervention participants and $74(71.8 \%)$ control participants completed 4-months post baseline measurements. Figure 1 shows the flow of participants through the study in detail. Based on data gathered in the online process evaluation questionnaire, each video was watched by $93.3-100 \%$ of parents from the intervention group. Consequently, it was not relevant to

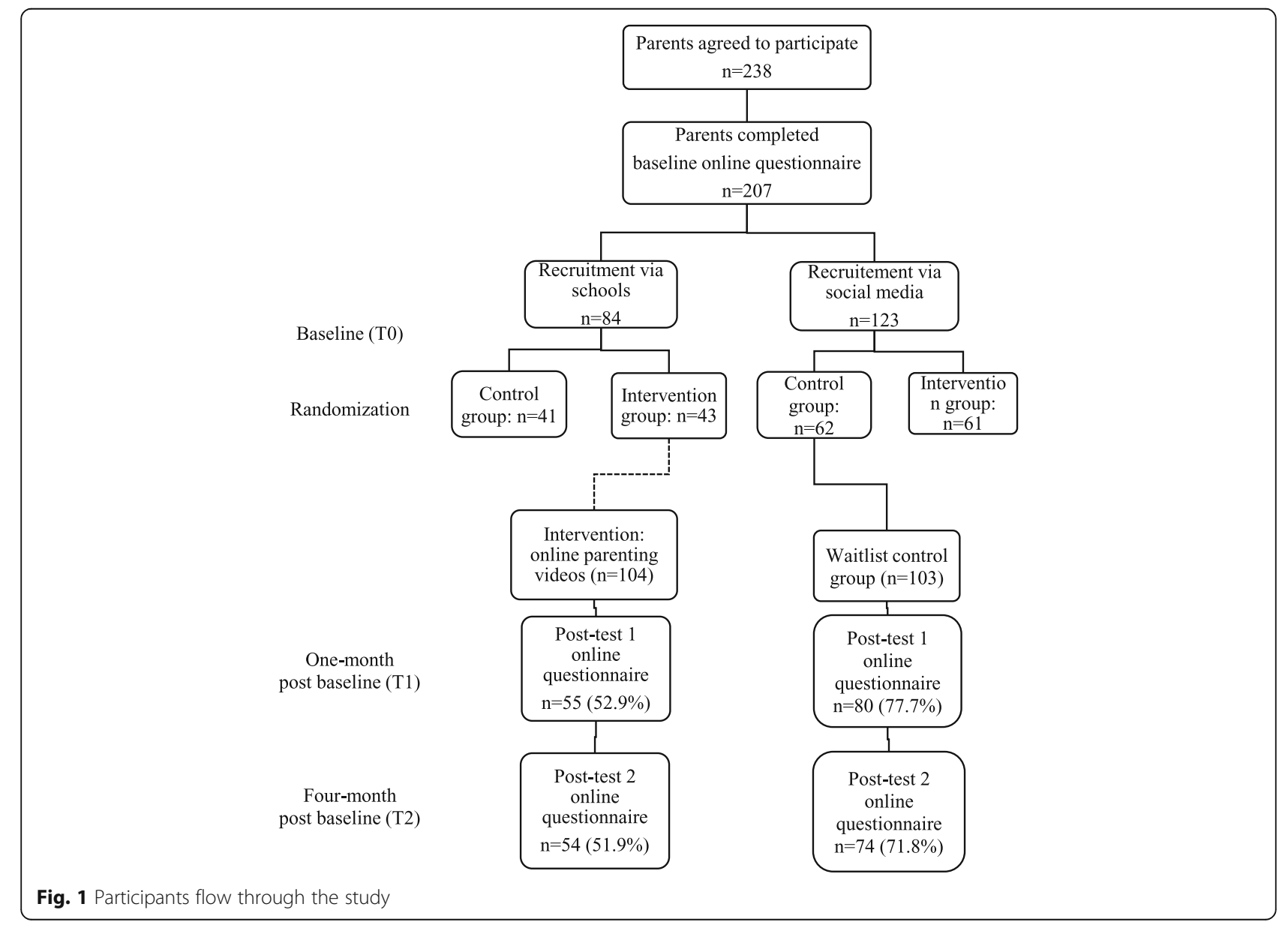


measure if intervention effects differed between parents who did and did not watch the videos.

Drop-out analyses indicated that participants from the intervention group ( $x^{2}=4.10, p=0.04$, two-tailed) were more likely to drop out. No significant differences were found for demographic variables, PA or screen-time of the child between parents who completed all measurements and parents who only filled out one or two questionnaires (Table 2).

Baseline characteristics of the intervention and control group are presented in Table 3. Control and intervention groups appear balanced on all demographic variables at baseline except for borderline significant differences in child's age, number of children per family and baseline PA levels of the primary schoolchild (Table 3).

\section{Intervention effects on children's behavior}

The Repeated Measures MANOVA analyses demonstrated that the intervention had no effect on children's health behaviors reported by parents between baseline and 1-month follow-up ( $\mathrm{F}=0.15 ; p=0.99)$ and between baseline and 4-months follow-up ( $\mathrm{F}=0.79 ; p=0.59)$ (Additional file 3: Table S2).

In the following paragraph, the intervention effects on parenting practices and parental self-efficacy are described. Only the significant and borderline significant

Table 2 Drop-out analysis

\begin{tabular}{|c|c|c|c|c|}
\hline Characteristic & $\begin{array}{l}\text { Completers } \\
(n=110)\end{array}$ & $\begin{array}{l}\text { Non } \\
\text { Completers } \\
(n=97)\end{array}$ & $\begin{array}{l}\text { Group } \\
\text { comparison }\end{array}$ & $P$-value \\
\hline Group, n (\%) & & & $x^{2}=4.10$ & .04 \\
\hline Intervention & 48 (43.6) & $56(57.7)$ & & \\
\hline Control & $62(56.4)$ & $41(42.3)$ & & \\
\hline \multicolumn{5}{|l|}{ Demographic variable } \\
\hline Gender parent, n (\%) & & & $x^{2}=0.02$ & .90 \\
\hline Male & $13(11.8)$ & $12(12.4)$ & & \\
\hline Female & $97(88.2)$ & 85 (87.6) & & \\
\hline $\begin{array}{l}\text { Age parent, } \\
\text { mean (SD) }\end{array}$ & $40.1(4.3)$ & $40.3(5.7)$ & $t=0.28$ & .78 \\
\hline $\begin{array}{l}\text { BMI mother, } \\
\text { mean (SD) }\end{array}$ & $23.8(4.1)$ & $23.8(4.4)$ & $t=-0.04$ & .97 \\
\hline $\begin{array}{l}\text { BMl father, } \\
\text { mean (SD) }\end{array}$ & $25.0(3.6)$ & $24.6(3.0)$ & $t=-0.69$ & .49 \\
\hline SES, n (\%) & & & $x^{2}=0.05$ & .82 \\
\hline Low & $18(16.4)$ & $17(17.5)$ & & \\
\hline Medium-High & $92(83.6)$ & $80(82.5)$ & & \\
\hline $\begin{array}{l}\text { Children's PA level, } \\
\text { mean minutes/day } \\
\text { (SD) }\end{array}$ & $54.1(29.7)$ & $48.5(31.5)$ & $t=-1.31$ & .19 \\
\hline $\begin{array}{l}\text { Children's screen-time, } \\
\text { mean minutes/day } \\
\text { (SD) }\end{array}$ & $128.1(73.4)$ & $132.3(78.3)$ & $t=0.39$ & .70 \\
\hline
\end{tabular}

results are reported in the text, and can be found in Table 4. The non-significant results can be found in Additional file 3: Table S2.

\section{Intervention effects on parenting practices}

Regarding PA and screen-time, the two-way interaction effects showed that the intervention-parents had a borderline significant increase for 'involving your child in household chores' ( $\mathrm{F}=4.78 ; p=0.03 ; \mathrm{d}=0.33$ ) at 1-month follow-up compared to the control group. No significant intervention effects were found on parenting practices concerning fruit, vegetable, water, soft drink and snack consumption between baseline and 1-month follow-up (Additional file 3: Table S2).

Between baseline and 4-months follow-up, there was only a significant positive intervention effect on 'motivating your child to eat fruit' $(\mathrm{F}=8.00 ; p=0.006 ; \mathrm{d}=0.61)$ (Additional file 3: Table S2).

\section{Intervention effects on parental self-efficacy related to parenting practices}

Intervention parents had a borderline significant increase in their 'self-efficacy for being physically active themselves' ( $\mathrm{F}=4.05 ; p=0.046 ; \mathrm{d}=0.26$ ) at 1-month follow-up compared to the control group (Additional file 3: Table S2).

At 4-months follow-up, intervention group parents had a borderline significant increase in their 'self-efficacy for motivating your child to eat vegetables' $(\mathrm{F}=4.95 ; p=0.03 ; \mathrm{d}=0.37)$ and 'self-efficacy for giving your child as much freedom as possible to drink water' $(\mathrm{F}=6.07 ; p=0.02 ; \mathrm{d}=0.50)$ compared to control group parents. Unexpectedly, parents of the intervention group had a significant decrease in their 'self-efficacy concerning having vegetables available' ( $\mathrm{F}=4.79 ; p=0.03 ; \mathrm{d}=-0.35)$ after 4 months (Additional file 3: Table S2).

\section{Moderating effects of child's age, gender and parental SES Child's age}

Parenting practices From baseline to 1-month follow-up, the time" group"age interaction effect was borderline significant for 'following up your rules concerning soft drink consumption' ( $\mathrm{F}=4.43 ; p=0.04)$ (Additional file 3: Table S2). However, stratified analyses showed no significant intervention effects for younger or older children (Additional file 4: Table S3).

From baseline to 4-months follow-up, the time*group*age interaction effect was significant or borderline significant for 'following up your rules concerning TV-time' ( $\mathrm{F}=6.75 ; p=0.011)$, 'giving an explanation concerning TV' ( $\mathrm{F}=9.06 ; p=0.004)$, 'giving an explanation 
Table 3 Comparison of baseline characteristics

\begin{tabular}{|c|c|c|c|c|}
\hline Characteristic & Intervention group $(n=104)$ & Control group $(n=103)$ & Group comparison & $P$-value \\
\hline \multicolumn{5}{|l|}{ Demographic variable } \\
\hline Gender parent, n (\%) & & & $x^{2}=0.06$ & .81 \\
\hline Male & $12(11.5)$ & $13(12.6)$ & & \\
\hline Female & $92(88.5)$ & $90(87.4)$ & & \\
\hline Gender child, n (\%) & & & $x^{2}=0.81$ & .37 \\
\hline Male & $57(54.8)$ & $50(48.5)$ & & \\
\hline Female & $47(45.2)$ & $53(51.5)$ & & \\
\hline Age parent, mean (SD) & $40.5(4.7)$ & $39.9(5.3)$ & $t=-0.80$ & .43 \\
\hline Age child, mean (SD) & $9.2(1.5)$ & $9.6(1.6)$ & $t=1.94$ & .05 \\
\hline BMI mother, mean (SD) & $23.5(4.2)$ & $24.1(4.3)$ & $t=1.01$ & .31 \\
\hline BMI father, mean (SD) & $24.9(3.2)$ & $24.7(3.4)$ & $t=-0.50$ & .62 \\
\hline SES, n (\%) & & & $x^{2}=0.05$ & .83 \\
\hline Low & $17(16.3)$ & $18(17.5)$ & & \\
\hline Medium-High & $87(83.7)$ & $85(82.5)$ & & \\
\hline Number of children per family, mean (SD) & $2.2(0.9)$ & $2.4(0.7)$ & $t=1.77$ & .08 \\
\hline Children's PA level, mean minutes/day (SD) & $46.6(27.0)$ & $55.3(33.5)$ & $t=1.81$ & .07 \\
\hline Children's screen-time, mean minutes/day (SD) & $122.9(66.0)$ & 137.1 (83.7) & $t=1.32$ & .19 \\
\hline
\end{tabular}

Significant $\mathrm{p}$-values $(p<0.05)$ are indicated in bold; borderline significant $p$-values $(0.05 \leq p<0.10)$ are indicated in bold italic

concerning gaming' ( $\mathrm{F}=6.65 ; p=0.012)$, 'permissiveness concerning how much vegetables your child is allowed to eat between meals' ( $\mathrm{F}=4.54 ; p=0.035)$, 'permissiveness concerning when your child is allowed to drink water' $(\mathrm{F}=6.86 ; p=0.010)$ and 'giving an explanation concerning soft drinks' $(\mathrm{F}=4.08 ; p=0.047)$ (see Additional file 3: Table S2). Stratified analyses showed that there were only significant or borderline significant intervention effects among parents of older children (10-12 year old): intervention group parents reported less 'giving an explanation concerning TV' $(\mathrm{F}=5.37 ; p=0.03 ; \mathrm{d}=-0.85)$ and 'giving an explanation concerning gaming' $(\mathrm{F}=5.04 ; p=0.03 ; \mathrm{d}=-0.81)$, and reported more 'permissiveness concerning how much vegetables your child is allowed to eat between meals' $(\mathrm{F}=11.70 ; p<0.001 ; \mathrm{d}=0.76) 4$ months later (Additional file 4: Table S3).

Parental self-efficacy From baseline to 1-month followup, the time* group*age interaction effect was significant or borderline significant for 'parental self-efficacy concerning giving choice for PA' ( $\mathrm{F}=4.52 ; p=0.04)$, 'limiting your own gaming (modeling)' $(\mathrm{F}=6.25$; $p=0.014$ ), 'letting your child choose between different kinds of fruit' ( $\mathrm{F}=10.06 ; p=0.002)$, 'availability of fruit' $(\mathrm{F}=5.64 ; p=0.02)$, 'availability of vegetables' $(\mathrm{F}=9.63$; $p=0.002)$ and giving an explanation concerning soft drinks' ( $\mathrm{F}=4.27 ; p=0.04$ ) (Additional file 3: Table S2). Stratified analyses showed that there were only significant or borderline significant intervention effects among parents of younger children (6-9 year old): intervention group parents reported a higher 'self-efficacy concerning limiting your own gaming' $(\mathrm{F}=6.47 ; p=0.014$; $\mathrm{d}=0.62$ ), 'self-efficacy concerning letting your child choose between different kinds of fruit' $(\mathrm{F}=8.38$; $p=0.005 ; \mathrm{d}=0.97)$, 'self-efficacy concerning having fruit available' $(\mathrm{F}=5.06 ; p=0.03 ; \mathrm{d}=0.66)$ and 'selfefficacy concerning having vegetables available' $(\mathrm{F}=5.80 ; p=0.02 ; \mathrm{d}=0.79)$ at 1 month follow-up (Additional file 4: Table S3).

From baseline to 4-months follow-up, the time*group*age interaction effect was borderline significant for 'parental self-efficacy concerning letting your child ask for permission to play games' ( $\mathrm{F}=4.25 ; p=0.04)$, 'self-efficacy concerning involving your child in buying fruit' ( $\mathrm{F}=4.85 ; p=0.03)$ and 'self-efficacy concerning involving your child in buying vegetables' $(F=6.00$; $p=0.02$ ). Stratified analyses showed that there were only borderline significant intervention effects among parents of younger children (6-9 year old): intervention group parents reported a higher self-efficacy concerning letting your child ask for permission to play games $(\mathrm{F}=4.95 ; p=0.03 ; \mathrm{d}=0.64)$ and concerning involving your child in buying vegetables $(\mathrm{F}=5.56 ; p=0.02 ; \mathrm{d}=0.73)$ after 4 months (Additional file 4: Table S3).

\section{Child's gender}

The time*group"gender interaction effect was only significant or borderline significant for 'parental self-efficacy on 
Table 4 Significant and borderline significant two-way and three-way interaction effects on parenting practices and parental self-efficacy

\begin{tabular}{|c|c|c|c|c|c|c|c|c|c|c|c|c|}
\hline \multicolumn{13}{|l|}{ Parenting practices from $\mathrm{T} 0$ to $\mathrm{T} 1$} \\
\hline \multirow[t]{2}{*}{ Univariate } & & \multirow[t]{2}{*}{$n$} & \multirow{2}{*}{$\begin{array}{c}\text { T0 } \\
\text { Mean (SD) }\end{array}$} & \multirow{2}{*}{$\begin{array}{c}\text { T1 } \\
\text { Mean (SD) }\end{array}$} & \multicolumn{2}{|c|}{$\begin{array}{l}\text { Time } x \\
\text { Group }\end{array}$} & \multicolumn{2}{|c|}{$\begin{array}{c}\text { Time } \times \text { Group } \\
\times \text { Age }\end{array}$} & \multicolumn{2}{|c|}{$\begin{array}{l}\text { Time } \times \text { Group } \\
\text { x Gender }\end{array}$} & \multicolumn{2}{|c|}{$\begin{array}{l}\text { Time } \times \text { Group } \\
\times \text { Parental SES }\end{array}$} \\
\hline & & & & & F & $P$ & $\mathrm{~F}$ & $P$ & $\mathrm{~F}$ & $P$ & $\mathrm{~F}$ & $P$ \\
\hline \multirow[t]{2}{*}{ Involving in household chores } & IG & 44 & $3.20(0.77)$ & $3.30(0.77)$ & 4.78 & 0.031 & 3.09 & 0.082 & 0.34 & 0.559 & 0.20 & 0.653 \\
\hline & CG & 70 & $3.04(0.84)$ & $2.87(0.90)$ & & & & & & & & \\
\hline \multirow[t]{2}{*}{ Rules concerning TV } & IG & 41 & $0.78(0.42)$ & $0.85(0.36)$ & 0.00 & 0.971 & 2.02 & 0.159 & 0.49 & 0.486 & 6.48 & 0.012 \\
\hline & CG & 66 & $0.80(0.40)$ & $0.88(0.33)$ & & & & & & & & \\
\hline \multirow[t]{2}{*}{ Rules concerning gaming } & IG & 37 & $0.78(0.42)$ & $0.86(0.35)$ & 1.16 & 0.285 & 2.88 & 0.093 & 0.00 & 0.968 & 4.62 & 0.034 \\
\hline & $C G$ & 61 & $0.75(0.43)$ & $0.92(0.28)$ & & & & & & & & \\
\hline \multirow[t]{2}{*}{ Modeling concerning TV } & IG & 45 & $4.00(0.95)$ & $3.91(0.97)$ & 1.79 & 0.183 & 3.24 & 0.075 & 1.18 & 0.280 & 5.50 & 0.021 \\
\hline & $C G$ & 69 & $3.43(1.16)$ & $3.59(1.05)$ & & & & & & & & \\
\hline \multirow[t]{2}{*}{ Modeling concerning gaming } & IG & 45 & $3.89(0.93)$ & $3.60(0.96)$ & 2.42 & 0.123 & 0.01 & 0.905 & 0.70 & 0.403 & 7.80 & 0.006 \\
\hline & CG & 69 & $3.35(0.98)$ & $3.35(0.94)$ & & & & & & & & \\
\hline \multirow{2}{*}{$\begin{array}{l}\text { Permissiveness concerning water } \\
\text { (how much) }\end{array}$} & IG & 50 & $4.32(0.98)$ & $4.58(0.70)$ & 3.56 & 0.062 & 0.09 & 0.764 & 1.44 & 0.233 & 4.32 & 0.040 \\
\hline & CG & 69 & $4.62(0.71)$ & $4.48(0.87)$ & & & & & & & & \\
\hline \multirow[t]{2}{*}{ Being consistent concerning soft drinks } & IG & 31 & $4.48(0.51)$ & $4.45(0.51)$ & 0.05 & 0.826 & 4.43 & 0.039 & 1.57 & 0.215 & 0.56 & 0.456 \\
\hline & $C G$ & 42 & $4.48(0.51)$ & $4.40(0.59)$ & & & & & & & & \\
\hline
\end{tabular}

Parenting practices from T0 to T2

Univariate

Modeling of PA

Being consistent concerning TV

Giving an explanation concerning TV

Giving an explanation concerning gaming

Modeling concerning TV

Motivating concerning fruit

Permissiveness concerning how much vegetables between meals

Permissiveness concerning water (when)

Choice concerning water

Being consistent concerning soft drinks n TO

$\mathrm{T} 2$

Time x Group

Mean (SD) Mean (SD)

IG $\quad 49 \quad 3.27(1.13) \quad 3.27(1.09)$

CG $\quad 63 \quad 3.19(1.19) \quad 3.19(1.13)$

IG $\quad 37 \quad 4.03(0.55) \quad 1.19(0.66)$

CG $\quad 45 \quad 3.89(0.57) \quad 3.93(0.58)$

IG $\quad 37 \quad 4.22(0.85) \quad 4.24(0.83)$

CG $\quad 45 \quad 4.09(0.85) \quad 4.18(0.68)$

IG 28

CG 40

IG $\quad 40 \quad 3.40(1.30) \quad 3.85(0.92)$

CG $\quad 54 \quad 3.57(1.08) \quad 3.72(1.00)$

IG $\quad 50 \quad 3.96(0.97) \quad 4.16(0.98)$

CG $\quad 63 \quad 3.49(1.20) \quad 3.46(1.15)$

IG $\quad 51 \quad 4.04(1.26) \quad 4.47(1.03)$

CG $\quad 66 \quad 4.08(1.13) \quad 3.79(1.21)$

IG $\quad 50 \quad 3.70(1.22) \quad 3.94(1.06)$

CG $\quad 66 \quad 4.02(1.10) \quad 4.00(0.93)$

IG $\quad 50 \quad 4.70(0.79) \quad 4.58(0.79)$

CG $\quad 66 \quad 4.79(0.60) \quad 4.71(0.58)$

IG $\quad 52 \quad 2.87(1.52) \quad 2.83(1.41)$

CG $\quad 66 \quad 3.24(1.55) \quad 3.36(1.41)$

IG $\quad 34 \quad 4.38(0.49) \quad 4.41(0.61)$

CG $\quad 47 \quad 4.45(0.54) \quad 4.47(0.58)$

F
Time x Group Time x Group Time x Group $\times$ Age $\times$ Gender $\times$ Parental SES

$\begin{array}{llllllll}0.00 & 1.000 & 0.34 & 0.563 & 1.12 & 0.291 & 4.64 & \mathbf{0 . 0 3 4}\end{array}$

$\begin{array}{llllllll}0.73 & 0.396 & 6.75 & \mathbf{0 . 0 1 1} & 1.06 & 0.306 & 0.72 & 0.399\end{array}$

$\begin{array}{llllllll}0.10 & 0.750 & 9.06 & \mathbf{0 . 0 0 4} & 1.88 & 0.175 & 0.02 & 0.891\end{array}$

$\begin{array}{llllllll}0.29 & 0.591 & 6.65 & \mathbf{0 . 0 1 2} & 0.59 & 0.444 & 0.29 & 0.593\end{array}$

$\begin{array}{llllllll}1.84 & 0.178 & 2.63 & 0.108 & 2.40 & 0.125 & 5.10 & \mathbf{0 . 0 2 6}\end{array}$

$\begin{array}{llllllll}1.57 & 0.213 & 0.31 & 0.578 & 0.01 & 0.906 & 5.14 & \mathbf{0 . 0 2 5}\end{array}$

$\begin{array}{llllllll}8.00 & \mathbf{0 . 0 0 6} & 0.24 & 0.624 & 0.18 & 0.677 & 1.69 & 0.196\end{array}$

$\begin{array}{llllllll}1.67 & 0.198 & 4.54 & \mathbf{0 . 0 3 5} & 0.41 & 0.524 & 0.01 & 0.930\end{array}$

$\begin{array}{llllllll}0.10 & 0.749 & 6.86 & \mathbf{0 . 0 1 0} & 0.01 & 0.914 & 3.57 & 0.061\end{array}$

$\begin{array}{llllllll}0.56 & 0.455 & 0.02 & 0.885 & 0.13 & 0.723 & 6.08 & \mathbf{0 . 0 1 5}\end{array}$

$\begin{array}{llllllll}0.00 & 0.950 & 0.09 & 0.761 & 1.75 & 0.189 & 8.43 & \mathbf{0 . 0 0 5}\end{array}$ 
Table 4 Significant and borderline significant two-way and three-way interaction effects on parenting practices and parental self-efficacy (Continued)

\begin{tabular}{|c|c|c|c|c|c|c|c|c|c|c|c|c|}
\hline \multirow{2}{*}{$\begin{array}{l}\text { Giving an explanation concerning } \\
\text { soft drinks }\end{array}$} & IG & 34 & $4.59(0.70)$ & $4.29(0.72)$ & \multirow[t]{2}{*}{0.17} & \multirow[t]{2}{*}{0.677} & \multirow[t]{2}{*}{4.08} & \multirow[t]{2}{*}{0.047} & \multirow[t]{2}{*}{0.60} & \multirow[t]{2}{*}{0.440} & \multirow[t]{2}{*}{0.88} & \multirow[t]{2}{*}{0.351} \\
\hline & CG & 46 & $4.59(0.65)$ & $4.22(0.92)$ & & & & & & & & \\
\hline \multicolumn{13}{|l|}{ Parental self-efficacy from T0 -toT1 } \\
\hline \multirow[t]{2}{*}{ Univariate } & & \multirow[t]{2}{*}{$\mathrm{n}$} & TO & T1 & \multicolumn{2}{|c|}{ Time $\times$ Group } & \multicolumn{2}{|c|}{$\begin{array}{c}\text { Time } \times \text { Group } \\
\text { x Age }\end{array}$} & \multicolumn{2}{|c|}{$\begin{array}{l}\text { Time } \times \text { Group } \\
\text { x Gender }\end{array}$} & \multicolumn{2}{|c|}{$\begin{array}{l}\text { Time } \times \text { Group } \\
\text { x Parental SES }\end{array}$} \\
\hline & & & Mean (SD) & Mean (SD) & $\mathrm{F}$ & $P$ & $\mathrm{~F}$ & P & $\mathrm{F}$ & P & $\mathrm{F}$ & $P$ \\
\hline \multirow[t]{2}{*}{ SE Modeling of PA } & IG & 44 & $3.16(1.38)$ & $3.64(1.30)$ & \multirow[t]{2}{*}{4.05} & \multirow[t]{2}{*}{0.046} & \multirow[t]{2}{*}{0.03} & \multirow[t]{2}{*}{0.862} & \multirow[t]{2}{*}{1.00} & \multirow[t]{2}{*}{0.319} & \multirow[t]{2}{*}{0.00} & \multirow[t]{2}{*}{0.990} \\
\hline & CG & 69 & $3.13(1.40)$ & $3.25(1.29)$ & & & & & & & & \\
\hline \multirow[t]{2}{*}{ SE Giving choice for PA } & IG & 44 & $4.39(0.75)$ & $4.25(0.94)$ & \multirow[t]{2}{*}{1.07} & \multirow[t]{2}{*}{0.304} & \multirow[t]{2}{*}{4.52} & \multirow[t]{2}{*}{0.036} & \multirow[t]{2}{*}{0.28} & 0.598 & 0.03 & 0.875 \\
\hline & CG & 67 & $4.33(0.88)$ & $4.36(0.85)$ & & & & & & & & \\
\hline SE Modeling concerning gaming & IG & 44 & $4.07(1.00)$ & $4.05(1.01)$ & 1.11 & 0.294 & 6.25 & 0.014 & 0.00 & 0.959 & 1.05 & 0.307 \\
\hline & CG & 70 & $4.16(0.96)$ & $3.93(0.98)$ & & & & & & & & \\
\hline SE Motivating concerning fruit & IG & 23 & $3.48(1.27)$ & $3.57(1.31)$ & 0.35 & 0.557 & 3.88 & 0.054 & 1.45 & 0.234 & 4.85 & 0.032 \\
\hline & CG & 35 & $3.09(1.44)$ & $3.46(1.27)$ & & & & & & & & \\
\hline SE Choice concerning fruit & IG & 46 & $4.20(1.02)$ & $4.43(0.83)$ & 1.12 & 0.292 & 10.06 & 0.002 & 0.11 & 0.738 & 0.98 & 0.325 \\
\hline & CG & 67 & $4.46(0.86)$ & $4.46(0.64)$ & & & & & & & & \\
\hline SE Availability of fruit & IG & 47 & $4.70(0.69)$ & $4.79(0.55)$ & 0.79 & 0.375 & 5.64 & 0.019 & 0.00 & 0.979 & 3.85 & 0.052 \\
\hline & CG & 67 & $4.84(0.41)$ & $4.81(0.47)$ & & & & & & & & \\
\hline SE Modeling concerning vegetables & IG & 46 & $4.87(0.40)$ & $4.87(0.40)$ & 0.87 & 0.353 & 0.28 & 0.599 & 5.69 & 0.019 & 0.20 & 0.658 \\
\hline & CG & 68 & $4.88(0.37)$ & $4.79(0.48)$ & & & & & & & & \\
\hline SE Availability of vegetables & IG & 47 & $4.72(0.54)$ & $4.77(0.56)$ & 0.01 & 0.932 & 9.63 & 0.002 & 0.21 & 0.650 & 1.26 & 0.264 \\
\hline & CG & 67 & $4.73(0.59)$ & $4.77(0.56)$ & & & & & & & & \\
\hline SE Giving an explanation concerning & IG & 30 & $4.57(0.63)$ & $4.63(0.56)$ & 0.28 & 0.601 & 4.27 & 0.043 & 8.62 & 0.005 & 0.00 & 0.968 \\
\hline oft drinks & CG & 42 & $4.57(0.74)$ & $4.50(0.92)$ & & & & & & & & \\
\hline
\end{tabular}

Parental self-efficacy from T0 to T2

Univariate

SE Permission concerning gaming

IG $\quad 50 \quad 4.30(0.87) \quad 4.20(1.09)$ $0.78 \quad 0.380$

$\mathrm{F}$

0.042 0.306 F $P$

CG $\quad 65 \quad 4.35(0.87) \quad 4.06(1.03)$

IG $\quad 51 \quad 4.29(0.88) \quad 4.45(1.03)$

$\begin{array}{lll}0.72 & 0.398 & 4.85\end{array}$

0.03

CG $\quad 67 \quad 4.55(0.82) \quad 4.54(0.78)$

SE Motivating concerning vegetables

IG $\quad 41 \quad 3.05(1.38) \quad 3.66(1.22)$

$$
\text { 4. }
$$

$$
\text { IG } \quad 51 \quad 4.78(0.46) \quad 4.69(0.58)
$$$$
4.79
$$$$
\text { CG } \quad 66 \quad 4.68(0.64) \quad 4.79(0.51)
$$

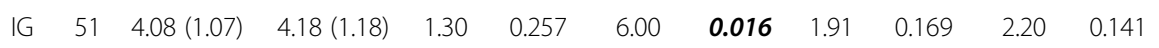

SE Involving concerning vegetables

CG $\quad 66 \quad 4.48(0.85) \quad 4.35(0.95)$

$\begin{array}{lllllllllllll}\text { SE Permissiveness concerning water (when) } & \text { IG } & 48 & 4.17(1.33) & 4.56(0.71) & 6.07 & \mathbf{0 . 0 1 5} & 0.08 & 0.777 & 0.00 & 0.996 & 0.11 & 0.742\end{array}$

CG $\quad 62 \quad 4.73(0.58) \quad 4.63(0.79)$

IG intervention group, CG control group, SE self-efficacy

Significant $p$-values are indicated in bold; borderline significant $p$-values are indicated in bold italic

All intervention effects (significant and non-significant) can be found in Additional file 3: Table S2 
eating vegetables in front of your child (modeling)' $(\mathrm{F}=5.69 ; p=0.02)$ and 'parental self-efficacy on giving your child an explanation why there are rules about soft drinks' ( $\mathrm{F}=8.62 ; p=0.005$ ) from baseline to 1-month follow-up (Additional file 3: Table S2). Stratified analyses showed that there was only a borderline significant intervention effect for 'parental self-efficacy concerning modeling of vegetables' among parents of boys $(\mathrm{F}=6.38$; $p=0.014 ; \mathrm{d}=0.79$ ): intervention group parents had a higher self-efficacy after the intervention. In contrast, the intervention effect for 'parental self-efficacy on giving your child an explanation why there are rules about soft drinks' was only borderline significant among parents of girls ( $\mathrm{F}=4.44 ; p=0.043 ; \mathrm{d}=1.33$ ): intervention group parents had a higher self-efficacy after the intervention (Additional file 4: Table S3).

\section{Parental SES}

Parenting practices From baseline to 1-month followup, the time* group*SES interaction effect was significant or borderline significant for 'rules concerning TV-time' $(\mathrm{F}=6.48 ; p=0.012)$, 'rules concerning gaming' ( $\mathrm{F}=4.62 ; p=0.03$ ), 'limiting your own TVtime' $(\mathrm{F}=5.50 ; p=0.02)$, 'limiting your own gaming' $(\mathrm{F}=7.80 ; p=0.006)$ and 'letting your child choose how much water he/she wants to drink' ( $\mathrm{F}=4.32$; $p=0.04)$. Stratified analyses showed no significant intervention effects on applying rules for TV-time or gaming among low or high SES families. Stratified analyses showed that there were only borderline significant intervention effects for 'limiting your own TV-time' ( $\mathrm{F}=5.75 ; p=0.03 ; \mathrm{d}=-1.23)$ and 'limiting your own gaming' $(\mathrm{F}=6.67 ; p=0.02 ; \mathrm{d}=-2.14$ ) among low SES families: intervention group parents had a lower performance of the parenting practices after the intervention. For 'letting your child choose how much water he/she wants to drink' ( $F=7.16$; $p=0.009 ; \mathrm{d}=0.74$ ) there was only a significant intervention effect among high SES families: intervention group parents were more permissive after the intervention (Additional file 4: Table S3).

From baseline to 4-months follow-up, the time*group*SES interaction effect was significant or borderline significant for 'being physically active yourself (modeling)' $(\mathrm{F}=4.64 ; p=0.03)$, 'monitoring gaming' $(\mathrm{F}=5.10$; $p=0.03$ ), 'limiting your own TV-time (modeling)' $(\mathrm{F}=5.14 ; p=0.03)$, 'being consistent concerning soft drinks' $(\mathrm{F}=8.43 ; p=0.005)$ and 'letting your child choose between different kinds of water' $(\mathrm{F}=6.08 ; p=0.02)$ (Additional file 3: Table S2). Stratified analyses showed that there was only a borderline significant intervention effect for 'letting your child choose between different kinds of water' ( $\mathrm{F}=5.87 ; p=0.03 ; \mathrm{d}=-0.95)$ among low
SES families: intervention group parents had a lower performance of the parenting practice after the intervention. On the other hand, there was only a borderline significant intervention effect for 'monitoring gaming' ( $\mathrm{F}=4.68$; $p=0.03 ; \mathrm{d}=0.46$ ) among high SES families: intervention group parents monitored their children more after the intervention. For 'modeling of PA', 'modeling concerning TV-time' and 'being consistent concerning soft drinks', no significant intervention effects for low or high SES families were found (Additional file 4: Table S3).

Self-efficacy From baseline to 1-month follow-up, the time"group"SES interaction effect was statistically significant for 'parental self-efficacy concerning motivating your child to eat fruit' ( $\mathrm{F}=4.85 ; p=0.03)$ (Additional file 3: Table S2). However, stratified analyses showed no significant intervention effects for low or high SES families (Additional file 4: Table S3).

\section{Discussion}

The current study investigated the effect of the online video intervention 'Movie Models' on children's PA, screen-time and healthy diet reported by parents; on specific parenting practices; and on parental self-efficacy related to these parenting practices. We also examined the potential moderating effects of child's age and gender and parental SES on the intervention effect.

The analyses demonstrated that the 'Movie Models' intervention had no effect on children's health behavior immediately and 3 months after the intervention. It could be that the follow-up period of measurement is too short. Because parental factors (parenting practices and parental self-efficacy) are a bridging function between the intervention and the child's behavior, it is possible that a longer period of time is necessary to change the child's health behavior. It is conceivable that if the changes in parenting practices and parental selfefficacy sustained over a longer time, changes in children's behavior may still occur. Also in the study of Naylor et al. (2016), changing parenting cognitions and practices in the home showed no effects on children's vegetable consumption, possibly also because of the short follow-up measurement period [52]. We would expect more effects on parenting practices and parental self-efficacy as the intervention specifically targeted those factors, but only a limited number of effects were found. Nevertheless, a clear tendency was found: the significant intervention effects were mainly on the more complex and less concrete parenting-related factors such as 'how you can motivate your child to eat fruit'. The parenting-related factors on which the intervention had no effect seemed to be rather simple, more concrete and more obvious such as 'having sports material at home', 
'reinforcing your child to eat fruit or vegetables, to drink water, to be physically active,...' and 'explaining your child why drinking water is important'. Furthermore, although there was only a limited number of effects, most effects were of moderate size. Therefore, this can be considered a positive and important finding of the intervention.

Several explanations can be given for the larger number of effects that were found on parenting-related factors related to healthy diet compared to PA and screen-time in the total sample. Firstly, the videos on healthy diet were put online in the first and second week of the intervention, and parents were still highly motivated in that period to apply the specific parenting practices in real life. Also literature shows that the interest in a web based program is higher at the start of the program [53]. Next, parenting practices and parental self-efficacy related to healthy diet might be easier to integrate in one's daily life because people eat at least three times a day, while PA and screen-time might be seen as supplemental to the biological needs such as feeding. Finally, also the review of Golley et al. showed that intervention effectiveness was in favor of interventions targeting energy intake/density and food choices [23].

Although the effects were rather limited in the total sample, more intervention effects were found in certain subgroups of parents. When considering the child's age as a moderator, the intervention had effect on six parenting-related factors in younger children (6-9 years old), whereas it only had an effect on three parentingrelated factors in older children (10-12 years old). It has been stated that parents play a major role in the development of healthy behavior of their primary schoolchildren [3, 12-14]. However, parental control begins to fade as the child grows older, and older primary schoolchildren get more freedom and decision-making power of their parents [54]. Therefore, it might be important that parents adopt specific parenting practices when their children are still young, and before an obesogenic lifestyle is deeply rooted. Furthermore, the results show that the intervention effects on parental self-efficacy related to PA, screen-time and healthy diet were all in parents of younger children (6-9 years old), whereas the intervention was only effective in changing parenting practices related to the three behaviors in older children (10-12 years old). An explanation could be that parents of younger children might still be searching on how they have to raise their children, suggesting that the parenting videos might have more effect on their self-efficacy concerning the parenting practices they have to adopt. It could therefore be argued that the intervention could focus on parents of younger children, but because parents often have more than one child in primary school and because there were also videos that affected parents of older children, it is recommended to promote the videos in all parents of primary school children. In contrast to children's age, gender did not moderate the effect of the 'Movie Models' intervention on parenting practices and parental self-efficacy. While gender seemed to be the most important moderator in interventions according to the review of Yildirim and colleagues [55] (interventions appeared to work better for girls than for boys), the current study shows that there was no difference in intervention effect between parents with a daughter or a son. This way, the online videos do not have to be differentiated between parents of boys and girls.

A final aspect that we would like to elaborate on is that for parental self-efficacy concerning having vegetables available (in the overall model) and for some subgroup analyses, the results showed inverse effects of the intervention (e.g., parents of the intervention group had a significant decrease in their self-efficacy after 4 months). A potential explanation is that parents could have been reflective on the answers they gave on the questionnaire. After watching the online videos in which parenting practices are showed, parents might realize that certain parenting practices are more difficult to implement than thought before. This may cause a decreased score in the parental self-efficacy after the intervention. This phenomenon has been described before in a paper reporting on the short term effects of the UP4FUN intervention. This familyinvolved school-based intervention aiming at reducing and breaking up sitting time at home and breaking up sitting time in school among 10-12 year olds in Europe also showed significant effects on attitude for computer/ games console use in favor of the control group [56].

\section{Strengths and limitations}

The strengths of the current study include the novel intervention which is based on formative research and the multiple follow-up measurement points. Furthermore, the program is theory driven, and is based on difficult everyday life situations experienced by parents. Finally, in the intervention group, each video was watched by $93.3-100 \%$ of parents which shows a great adherence. However, this study was also subject to some limitations. First, recruitment was difficult, and drop-out was higher than expected. Also in other studies, recruitment of parents has been challenging [57], or a relatively high number of participants withdrew from the study [19]. However, it should be stated that parents had to complete a bulky questionnaire three times. So it is possible that parents dropped out because of the questionnaire and not because they did not like the videos. Furthermore, only 84 of 207 participants were recruited via primary schools and therefore, clusters could not be accounted for in the analyses. However, because the 
number of children recruited via the same school was low, we consider the chance of social support through the school clustering as limited. Secondly, the self-report questionnaires may have led to social desirability bias. Thirdly, single item measures of the parenting practices were used which could increase measurement error. Next, the intervention reached parents who were predominantly of high SES and with children of healthy BMI. Also the criterion that only parents with internet access could be included in the study might pose a threat to the generalizability of the study findings. Only a limited number of parents of children who might be in greatest need, were reached by the intervention. Therefore, extra effort will be necessary to ensure that the intervention also reaches at-risk parents. Furthermore, because the combination of social desirability bias and the highly educated group of participating parents may have resulted in ceiling effects, the intervention could be a more promising parenting program for at-risk parents who have lower baseline values. Nevertheless, it is possible that low SES parents do not care to participate in social media campaigns. Therefore, different strategies should be performed to work with these at-risk parents. 'For example, low SES parents could be personally contacted by local community workers or local health providers who could encourage those parents to watch the videos. Finally, it is possible that a fivepoint answering format is not sensitive enough to measure the effect of the intervention. When parents already perform the parenting practice regularly at baseline, they will choose the answer category 'often' in the questionnaire. After the intervention, the parent might perform the behavior somewhat more, but not enough to report the highest level of frequency [58].

\section{Conclusions (main conclusions + importance and relevance)}

The 'Movie Models' intervention was effective in increasing some important parenting practices and parental self-efficacy related to PA, screen-time and healthy diet in children. Therefore, the current intervention study is an important first step in promoting effective parenting-related factors. However, it should be further explored if the intervention is able to increase children's healthy diet and PA and to decrease children's screen-time on the long term. Furthermore, future studies should investigate if 'Movie Models' is a promising parenting program for at-risk parents with low SES and with overweight/obese children. Because the online parenting videos could be easily, inexpensively and widely distributed to large numbers of parents, its public health effect might be maximized.

\section{Additional files}

Additional file 1: Table S1. Formulations and descriptive statistics of the questionnaire items of the specific parenting-related factors. (DOCX $26 \mathrm{~kb}$ )

Additional file 2: Table S4. Dataset. (XLSX 260 kb)

Additional file 3: Table S2. Two-way interaction effects on children's behavior, and two-way and three-way interaction effects on parenting practices and parental self-efficacy. (DOCX 100 kb)

Additional file 4: Table S3. Two-way interaction effects stratified by moderator. (DOCX $44 \mathrm{~kb}$ )

\section{Abbreviations}

ANOVA: Analysis of variance; BMl: Body mass index; PA: Physical activity; SES: Socio-economic status; T0: Baseline; T1: One month post baseline; T2: Four months post baseline

\section{Acknowledgements}

The authors wish to thank the participating schools, their students and the parents of the students.

\section{Funding}

This project is funded by the policy area 'Welfare, Public Health and Family'.

Availability of data and materials

Dataset is available as Additional file 2: Table S4.

Authors' contributions

$\mathrm{SDL}, \mathrm{MV}, \mathrm{GC}$ and IDB developed the information flyers and the online questionnaire. Furthermore, SDL and MV conducted the (moderated) Repeated Measure (Multivariate) ANOVA analyses. SDL drafted the manuscript. All authors revised the article critically for important intellectual content and approved the final manuscript

\section{Competing interests}

Sara De Lepeleere is a recipient of a PhD-scholarship from the Flemish Agency for Care and Health (B/12732/01) and is supported by the Research Foundation Flanders (FWO) (FWO14/ASP/066). Maïté Verloigne is supported by the FWO (postdoctoral research fellowship: FWO13/PDO/191). Greet Cardon and Ilse De Bourdeaudhuij have no financial disclosures. The authors declare that they have no competing interests.

Consent for publication

Not applicable.

Ethics approval and consent to participate

Ethical approval was provided by the Ethics Committee of the Ghent University Hospital (B670201214212) on June 6th 2012 (chairman Prof. dr. D. Matthys). This approval was administered before the study was conducted. Trial registration: EC/2012/317.

Consent was obtained by parents through the following way: Parents who wanted to participate had to send an email to the researcher. Afterwards, they were sent an information letter and the link to the online questionnaire, and were informed that by completing this online questionnaire, they gave consent to participate in the study.

\section{Publisher's Note}

Springer Nature remains neutral with regard to jurisdictional claims in published maps and institutional affiliations.

Received: 12 August 2016 Accepted: 12 April 2017

Published online: 27 April 2017

\section{References}

1. Berenson GS. Health consequences of obesity. Pediatr Blood Cancer. 2012; 58:117-21.

2. Ekelund U, Luan J, Sherar LB, Esliger DW, Griew P, Cooper A. Moderate to vigorous physical activity and sedentary time and cardiometabolic risk factors in children and adolescents. JAMA. 2012;307:704-12. 
3. Gerards SM, Sleddens EF, Dagnelie PC, de Vries NK, Kremers SP. Interventions addressing general parenting to prevent or treat childhood obesity. Int J Pediatr Obes. 2011;6:e28-45.

4. Helland SH, Bere E, Overby NC. Study protocol for a multi-component kindergarten-based intervention to promote healthy diets in toddlers: a cluster randomized trial. BMC Public Health. 2016;16:273.

5. Maffeis C. Aetiology of overweight and obesity in children and adolescents. Eur J Pediatr. 2000;159(Suppl 1):S35-44.

6. Magnusson MB, Sjoberg A, Kjellgren Kl, Lissner L. Childhood obesity and prevention in different socio-economic contexts. Prev Med. 2011;53:402-7.

7. de Jong E, Schokker DF, Visscher TL, Seidell JC, Renders CM. Behavioural and socio-demographic characteristics of Dutch neighbourhoods with high prevalence of childhood obesity. Int J Pediatr Obes. 2011;6:298-305.

8. Verloigne $M$, Van LW, Maes L, Yildirim M, Chinapaw M, Manios $Y$, Androutsos O, Kovacs E, Bringolf-Isler B, Brug J, De Bl. Levels of physical activity and sedentary time among 10- to 12-year-old boys and girls across 5 European countries using accelerometers: an observational study within the ENERGY-project. Int J Behav Nutr Phys Act. 2012;9:34.

9. Brug J, van Stralen MM, Te Velde SJ, Chinapaw MJ, De BI LN, Bere E, Maskini $V$, Singh AS, Maes L, et al. Differences in Weight Status and Energy-Balance Related Behaviors among Schoolchildren across Europe: The ENERGYProject. PLoS One. 2012;7:e34742.

10. Tremblay MS, LeBlanc AG, Janssen I, Kho ME, Hicks A, Murumets K, Colley RC, Duggan M. Canadian sedentary behaviour guidelines for children and youth. Appl Physiol Nutr Metab. 2011;36:59-64.

11. Patrick H, Hennessy E, McSpadden K, Oh A. Parenting styles and practices in children's obesogenic behaviors: scientific gaps and future research directions. Child Obes. 2013;9(Suppl):S73-86.

12. Lindsay AC, Sussner KM, Kim J, Gortmaker S. The role of parents in preventing childhood obesity. Futur Child. 2006;16:169-86.

13. Campbell K, Hesketh K, Crawford D, Salmon J, Ball K, McCallum Z. The Infant Feeding Activity and Nutrition Trial (INFANT) an early intervention to prevent childhood obesity: cluster-randomised controlled trial. BMC Public Health. 2008:8:103.

14. Trost SG, Loprinzi PD. Parental Influences on Physical Activity Behavior in Children and Adolescents: A Brief Review. Am J Lifestyle Med. 2011;5:171-81.

15. Ventura AK, Birch LL. Does parenting affect children's eating and weight status? Int J Behav Nutr Phys Act. 2008:5:15.

16. Sleddens EF, Kremers SP, Stafleu A, Dagnelie PC, de Vries NK, Thijs C. Food parenting practices and child dietary behavior. Prospective relations and the moderating role of general parenting. Appetite. 2014;79:42-50.

17. Rodenburg G, Kremers SP, Oenema A, van de Mheen D. Associations of children's appetitive traits with weight and dietary behaviours in the context of general parenting. PLoS One. 2012;7:e50642.

18. Baranowski T, Jago R. Understanding the mechanisms of change in children's physical activity programs. Exerc Sport Sci Rev. 2005;33:163-8.

19. Jago R, Sebire SJ, Turner KM, Bentley GF, Goodred JK, Fox KR, Stewart-Brown S, Lucas PJ. Feasibility trial evaluation of a physical activity and screenviewing course for parents of 6 to 8 year-old children: Teamplay. Int J Behav Nutr Phys Act. 2013;10:31.

20. Deci EL, Ryan RM. The "what" and "why" of goal pursuits: Human needs and the self-determination of behavior. Psychol Inq. 2000;11:227-68.

21. Deci EL. Why we do wat we do: understanding self-motivation. New York: Penguin; 1995

22. Grolnick WS, Deci EL, Ryan RM. Internalization within the family: the SelfDetermination Theory Perspective. In: Parenting and children's internalization of values: A handbook of contemporary theory. Grusec JE, Kuczynski L. Hoboken: Wiley; 1997. p. 135-161

23. Golley RK, Hendrie GA, Slater A, Corsini N. Interventions that involve parents to improve children's weight-related nutrition intake and activity patterns - what nutrition and activity targets and behaviour change techniques are associated with intervention effectiveness? Obes Rev. 2011;12:114-30.

24. Verloigne M, Bere E, Van LW, Maes L, Lien N, Vik FN, Brug J, Cardon G, De BI. The effect of the UP4FUN pilot intervention on objectively measured sedentary time and physical activity in 10-12 year old children in Belgium: the ENERGY-project. BMC Public Health. 2012;12:805.

25. Centis E, Marzocchi R, Di LR, Moscatiello S, Salardi S, Villanova N, Marchesini G. A controlled, class-based multicomponent intervention to promote healthy lifestyle and to reduce the burden of childhood obesity. Pediatr Obes. 2012;7:436-45.
26. O'Connor TM, Jago R, Baranowski T. Engaging parents to increase youth physical activity a systematic review. Am J Prev Med. 2009:37:141-9.

27. Zenzen W, Kridli S. Integrative review of school-based childhood obesity prevention programs. J Pediatr Health Care. 2009;23:242-58.

28. Shaya FT, Flores D, Gbarayor CM, Wang J. School-based obesity interventions: a literature review. J Sch Health. 2008;78:189-96.

29. Gonzalez-Suarez C, Worley A, Grimmer-Somers K, Dones V. School-based interventions on childhood obesity: a meta-analysis. Am J Prev Med. 2009; 37:418-27.

30. van Sluijs EM, McMinn AM, Griffin SJ. Effectiveness of interventions to promote physical activity in children and adolescents: systematic review of controlled trials. BMJ. 2007;335:703.

31. Stice E, Shaw H, Marti CN. A meta-analytic review of obesity prevention programs for children and adolescents: the skinny on interventions that work. Psychol Bull. 2006;132:667-91.

32. Plantin L, Daneback K. Parenthood, information and support on the internet. A literature review of research on parents and professionals online. BMC Fam Pract. 2009;10:34

33. Ruiter EL, Fransen GA, Molleman GR, van der Velden K, Engels RC. The effectiveness of a web-based Dutch parenting program to prevent overweight in children 9-13 years of age: study protocol for a two-armed cluster randomized controlled trial. BMC Public Health. 2015;15:148.

34. Onnerfalt J, Erlandsson LK, Orban K, Broberg M, Helgason C, ThorngrenJerneck K. A family-based intervention targeting parents of preschool children with overweight and obesity: conceptual framework and study design of LOOPS- Lund overweight and obesity preschool study. BMC Public Health. 2012;12:879.

35. Raat H, Struijk MK, Remmers T, Vlasblom E, van Grieken A, Broeren SM, te Velde SJ, Beltman M, Boere-Boonekamp MM, L'Hoir MP. Primary prevention of overweight in preschool children, the BeeBOFT study (breastfeeding, breakfast daily, outside playing, few sweet drinks, less TV viewing): design of a cluster randomized controlled trial. BMC Public Health. 2013;13:974

36. De Lepeleere S, DeSmet A, Verloigne M, Cardon G, De Bourdeaudhuij I. What practices do parents perceive as effective or ineffective in promoting a healthy diet, physical activity, and less sitting in children: parent focus groups. BMC Public Health. 2013;13:1067.

37. Brug J, Oenema A, Ferreira I. Theory, evidence and Intervention Mapping to improve behavior nutrition and physical activity interventions. Int J Behav Nutr Phys Act. 2005;2:2.

38. De Lepeleere S, Verloigne M, Brown HE, Cardon G, De Bourdeaudhuij I. Using the Intervention Mapping Protocol to develop an online video intervention for parents to prevent childhood obesity: Movie Models. Glob Health Promot. 2016;0:1-11.

39. Winkleby MA, Jatulis DE, Frank E, Fortmann SP. Socioeconomic status and health: how education, income, and occupation contribute to risk factors for cardiovascular disease. Am J Public Health. 1992;82:816-20.

40. Cole TJ, Bellizzi MC, Flegal KM, Dietz WH. Establishing a standard definition for child overweight and obesity worldwide: international survey. BMJ. 2000; 320:1240-3

41. Deforche B, De Bourdeaudhuij I, D'hondt E, Cardon G. Objectively measured physical activity, physical activity related personality and body mass index in 6- to 10-yr-old children: a cross-sectional study. Int I Behav Nutr Phys Act. 2009;6:25

42. Cancela JM, Ayan C, Castro A. An evaluation of questionnaires assessing physical activity levels in youth populations. J Child Health Care. 2013; 17:274-93.

43. Huybrechts I, De Backer G, De Bacquer D, Maes L, De Henauw S. Relative validity and reproducibility of a food-frequency questionnaire for estimating food intakes among Flemish preschoolers. Int J Environ Res Public Health. 2009:6:382-99.

44. Trost SG, Sallis JF, Pate RR, Freedson PS, Taylor WC, Dowda M. Evaluating a model of parental influence on youth physical activity. Am J Prev Med. 2003:25:277-82.

45. Larios SE, Ayala GX, Arredondo EM, Baquero B, Elder JP. Development and validation of a scale to measure Latino parenting strategies related to children's obesigenic behaviors. The parenting strategies for eating and activity scale (PEAS). Appetite. 2009:52:166-72.

46. Sleddens EF, Kremers SP, de Vries NK, Thijs C. Relationship between parental feeding styles and eating behaviours of Dutch children aged 6-7. Appetite. 2010;54:30-6. 
47. Sherwood NE, Taylor WC, Treuth M, Klesges LM, Baranowski T, Zhou A, Pratt C, McClanahan B, Robinson TN, Pruitt L, Miller W. Measurement characteristics of activity-related psychosocial measures in 8- to 10-year-old African-American girls in the Girls Health Enrichment Multisite Study (GEMS). Prev Med. 2004;38(Suppl):S60-8.

48. Decker JW. Initial development and testing of a questionnaire of parental self-efficacy for enacting healthy lifestyles in their children. J Spec Pediatr Nurs. 2012;17:147-58.

49. Crespo NC, Elder JP, Ayala GX, Slymen DJ, Campbell NR, Sallis JF, McKenzie $\mathrm{TL}$, Baquero B, Arredondo EM. Results of a Multi-level Intervention to Prevent and Control Childhood Obesity among Latino Children: The Aventuras Para Ninos Study. Ann Behav Med. 2012;43:84-100.

50. De Lepeleere S, De Bourdeaudhuij I, Cardon G, Verloigne M. Do specific parenting practices and related parental self-efficacy associate with physical activity and screen time among primary schoolchildren? A cross-sectional study in Belgium. BMJ Open. 2015;5:e007209.

51. Cohen J. Statistical power analysis for the behavioural sciences. 2nd ed. Hillsdale: Erlbaum; 1988.

52. Naylor PJ, Trill DG. Mind the Gap! A randomized comparison trial to explore the impact of a family-based vegetable cooking intervention for children and their parents. Submitted in International Journal of Behaviour Nutrition and Physical Activity. 2016.

53. Manicavasagar V, Horswood D, Burckhardt R, Lum A, Hadzi-Pavlovic D, Parker G. Feasibility and effectiveness of a web-based positive psychology program for youth mental health: randomized controlled trial. J Med Internet Res. 2014;16:e140.

54. Roberts BP, Blinkhorn AS, Duxbury JT. The power of children over adults when obtaining sweet snacks. Int J Paediatr Dent. 2003;13:76-84.

55. Yildirim M, van Stralen MM, Chinapaw MJ, Brug J, van Mechelen W, Twisk JW, Te Velde SJ. For whom and under what circumstances do school-based energy balance behavior interventions work? Systematic review on moderators. Int J Pediatr Obes. 2011;6:e46-57.

56. Vik FN, Lien N, Berntsen S, De Bl, Grillenberger M, Manios Y, Kovacs E, Chinapaw MJ, Brug J, Bere E. Evaluation of the UP4FUN intervention: a cluster randomized trial to reduce and break up sitting time in European 10-12-year-old children. PLoS One. 2015;10:e0122612.

57. Gerards SM, Dagnelie PC, Gubbels JS, van BS HFJ, Jansen MW, van der Goot $\mathrm{OH}$, de Vries NK, Sanders MR, Kremers SP. The effectiveness of lifestyle triple $P$ in the Netherlands: a randomized controlled trial. PLoS One. 2015;10: e0122240.

58. Portney LG, Watkins MP. Foundations of Clinical Research - Applications to Practice. 3rd ed. New Jersey: Pearson Education; 2009.

\section{Submit your next manuscript to BioMed Central and we will help you at every step:}

- We accept pre-submission inquiries

- Our selector tool helps you to find the most relevant journal

- We provide round the clock customer support

- Convenient online submission

- Thorough peer review

- Inclusion in PubMed and all major indexing services

- Maximum visibility for your research

Submit your manuscript at www.biomedcentral.com/submit

) Biomed Central 